\title{
BMJ Open Transgender people's reasons for primary care visits: a cross-sectional study in France
}

\author{
Maud Garnier, ${ }^{1}$ Sarah Ollivier, ${ }^{1}$ Marie Flori, ${ }^{1}$ Christine Maynié-François (1) ${ }^{1,2}$
}

To cite: Garnier M, Ollivier S, Flori M, et al. Transgender people's reasons for primary care visits: a cross-sectional study in France. BMJ Open 2021;11:e036895. doi:10.1136/ bmjopen-2020-036895

- Prepublication history and additional supplemental material for this paper are available online. To view these files, please visit the journal online (http://dx.doi.org/10.1136/ bmjopen-2020-036895).

Received 10 March 2020 Accepted 25 May 2021
Check for updates

(C) Author(s) (or their employer(s)) 2021. Re-use permitted under CC BY-NC. No commercial re-use. See rights and permissions. Published by BMJ.

${ }^{1}$ Collège Universitaire de Médecine Générale, Université Claude Bernard Lyon 1, Lyon, France

${ }^{2}$ UMR CNRS 5558, Laboratoire de biométrie et biologie évolutive (LBBE), équipe Evaluation et modélisation des effets thérapeutiques (EMET), Université Claude Bernard Lyon 1, Lyon, France

Correspondence to Dr Christine Maynié-François; christine.maynie-francois@ univ-lyon1.fr

\section{ABSTRACT}

Objectives Our main objective was to describe transgender people's reasons for consulting a general practitioner (GP) outside of transition-related issues; the secondary objective was to study the qualitative aspects of the primary care visits for this population.

Design Descriptive, cross-sectional study in France. Setting The study questionnaire was distributed online and to healthcare centres in France.

Participants Self-identified transgender people aged 18 and older.

Primary and secondary outcomes Reasons for consulting were collected retrospectively and classified according to the International Classification of Primary Care, second edition (ICPC-2). The answers to the openended questions were analysed qualitatively by theme and occurrences.

Results Out of 320 respondents, $50 \%$ visited their GP for a problem unrelated to their transition, with a total of 155 reported reasons. Procedures such as prescription renewal and administrative paperwork represented $33 \%$ of the reasons to visit, followed by general symptoms $(15 \%)$. Benevolence from the physician was the most important criteria for a successful consultation.

Conclusion Transgender people visit their GP for reasons either related $(50 \%)$ or unrelated $(50 \%)$ to transition. When unrelated, reasons appear to be similar to the reasons found in the general population. Further research and training should be developed on comprehensive primary healthcare for transgender people to provide quality patient-centred care for transgender patients.

\section{INTRODUCTION}

Between 1300 and 6500 individuals selfidentify as transgender in France (between $0.002 \%$ and $0.01 \%$ of the general population), that is, with a gender identity or gender expression different from the sex that they were assigned at birth. These numbers are probably underestimated: the last survey of the transgender population in France was conducted in 2009, ${ }^{1}$ and used stigmatising terms such as transexual, associated with gender-affirming surgery and no longer relevant to describe gender diversity. ${ }^{2}$

Although the visibility of the transgender community has improved over the past 10

\section{Strengths and limitations of this study}

To the best of our knowledge, this is the first study to explore transgender people's reasons to visit their general practitioner outside of transition-related reasons.

- All aspects of the study design, especially protocol and questionnaire, were discussed with members of a local trans civil rights organisation.

- Our questionnaire was distributed through trans organisations and healthcare centres to reach as many members of the trans population as possible while reducing selection bias.

- Memory bias may be the main limitation of our study due to its retrospective design.

years, transgender people still suffer from stigma and discrimination in healthcare, ${ }^{2-4}$ with an impact on their use of medical resources. In a study published in 2011 by the French organisation, Chrysalide, ${ }^{5} 16 \%$ of the respondents were denied a medical appointment because they were transgender, $35 \%$ gave up on medical care because of the physician's prejudices and $75 \%$ had at least once felt uncomfortable in the presence of medical staff because of their transidentity. In the Trans Mental Health and Well-being in Ireland survey conducted in 2013 by the Transgender Equality Network Ireland, ${ }^{6} 58 \%$ of the respondents reported that general health professionals used the wrong pronouns, either on purpose or by mistake, and $16 \%$ reported hurtful or insulting language about transgender people. Although discrimination in healthcare and lack of awareness among healthcare providers on transgender-related health issues are significant barriers to access healthcare for transgender patients, other barriers include health insurance policies and public policy. ${ }^{7}$

Most studies about transgender people's health focus on transitioning, such as genderaffirming surgery and hormone therapy. A systematic review in $2015^{8}$ found that 
among 75 studies published since 1977 on transgender people healthcare utilisation, $60 \%$ were about surgery and $20 \%$ on endocrinology. In the surveys published by the National Institute for Health Surveillance (Institut national de veille sanitaire, InVS) and the National Institute for Health and Medical Research (Institut national de la santé et de la recherche médicale, INSERM), ${ }^{9}{ }^{10}$ most of the health-related questions were about transgender people's progression in the transition process.

Most of the medical services for transgender people are provided by specialists, although a large part could be delivered by primary care providers. ${ }^{11}$ However, the stigma faced in healthcare by transgender people also impacts their utilisation of primary care.$^{12}$ On the providers' side, some data suggest that most primary care providers are willing to provide routine healthcare for transgender patients ${ }^{13}$ but only half are willing to continue genderaffirming hormone therapy. ${ }^{14}$ Some of the providers' attitudes are related to their knowledge of transgender issues and previous encounters with transgender people or patients.

To provide the best quality of primary care to transgender patients, it seems important to identify what transgender people expect from primary care, in terms of healthcare needs (gender-affirming related or not) and of patient-provider communication. A 2018 study found that the main health concerns of transgender individuals included sexual health, transition-related matters, reproductive health, body positivity and self-esteem, and mental health. ${ }^{15}$

The primary objective of our study was to describe transgender population's reasons for consulting a general practitioner (GP) other than reasons related to transitioning.

The secondary objectives were to describe transgender people's utilisation of primary healthcare, the difficulties they face and their expectations regarding their GP.

\section{METHODS}

We conducted a cross-sectional study among the transgender population in France.

\section{Study population}

Because of the discrimination they face, the transgender population is very discrete, they can be described as a hidden population. ${ }^{16}$ To reach as many people as possible, we used the snowball sampling approach, which consists in asking predetermined subjects to recruit further subjects they are acquainted with among a given population. In our study, the intermediaries were trans civil rights organisations, reproductive and sexual healthcare centres (such as Planned parenthood), HIV testing centres and university preventive medicine departments. Our recruitment plan was in accordance with previously published considerations on conducting transgender studies. ${ }^{16}$
Respondents would fill in an electronic questionnaire if they met the inclusion criteria of identifying as transgender, being 18 years or older and agreeing to participate in the study.

\section{Questionnaire}

The survey was available online from 1 November 2017 to 1 February 2018.

Questions regarding reasons to visit (primary objective) were as follow: 'Was your last visit to your GP related to transition?' (yes/no). 'If no, what were the reason or reasons of this visit?' (open-ended).

The questionnaire comprised a series of close-ended multiple-choice questions on respondents' habits with their GPs, some questions on respondents' demographic characteristics, and two open-ended questions about the problems met during consultations with GPs and about what respondents expected of their GP.

All questions were either facultative or included a 'No answer' proposition, so respondents would not feel compelled to give out personal information.

A translated version of the questionnaire is available as online supplemental material.

\section{Data collection}

We contacted 13 trans civil rights organisations, the reproductive and sexual healthcare centres of 170 cities, the preventive medicine departments of 55 universities and the HIV testing centres in 111 cities spread across France. For trans organisations, we first sent a message explaining our study, then we asked the organisations to share the link to our survey on their websites and social network pages. Sexual health and HIV testing centres, and university preventive medicine departments were sent by email a poster to be displayed in waiting rooms to inform patients of our study. Posters included the website link and a flashcode leading to the questionnaire. Respondents were encouraged to share the questionnaire.

The reasons for visits were sorted by three authors (MG, SO, CM-F), using the second version of the International Classification of Primary Care (ICPC-2), ${ }^{17}$ developed by the World Organization of National Colleges, Academies and Academic Associations of General Practitioners/ Family Physicians (WONCA).

\section{Patients and public involvement statement}

We met with the trans civil rights organisation Chrysalide representatives to discuss our project before we started to work on the protocol. We collaborated with Chrysalide representatives for every early aspect of the study: protocol, questionnaire design and sharing, to best fit our target population's experience. Such a collaboration with community representatives is particularly important in transgender studies, given the stigma and discrimination faced by transgender people. ${ }^{16}$

\section{Ethics and confidentiality}

The study was anonymous and informed consent was obtained from respondents after a description of the 
study and information on data use. Our questionnaire was hosted on LimeSurvey Professional.

\section{Data analysis}

We ran descriptive analyses for all quantitative variables. The answers to open-ended questions were analysed qualitatively, with a thematic analysis and counting of occurrences in verbatims. The thematic analysis was triangulated: two authors (MG and $\mathrm{SO}$ ) independently analysed the answers to the open-ended questions and coded the verbatims, a third author (CM-F) was consulted when there was a disagreement.

\section{Data statement}

Data are available on request.

\section{RESULTS}

\section{Sociodemographic characteristics}

Out of the 320 respondents, 181 (57\%) identified as transfeminine and 126 (39\%) identified as transmasculine. Sixty-five per cent were 40-year-old or less. The majority of respondents were either employed (27\%) or students $(26 \%)$. Most respondents $(n=240,75 \%)$ had a non-gender compatible social security number. The sociodemographic characteristics of the respondents are presented in table 1 . Most of the respondents $(n=179$, $56 \%$ ) heard about the study from an association, 98 $(31 \%)$ from a social network and $24(8 \%)$ from a relative.

Most of the respondents (93\%) had a GP officially declared to the French Health System. More than half of the respondents (53\%) found their GP by themselves without the help of a relative or an association.

For $31 \%$ of the respondents, the last consultation took place less than a month ago, and $49 \%$ less than 6 months ago.

\section{Reasons for consulting}

For $48 \%$ of respondents, the last visit with their GP was for a transition-related issue. Reasons unrelated to transition were cited by 135 respondents with a total of 155 reasons classified according to the ICPC-2. The most frequent ICPC-2 code was Process. The 52 coded process included 19 were medical follow-ups or prescription renewals and 18 were administrative procedures. The second most frequent code section was 'General and unspecified (A)' symptoms (23 occurrences) such as fever, weekness/tiredness or pain. Other code sections included 'Musculoskeletal (L)' (18 occurrences), 'Respiratory (S)' (15 occurrences) and 'Psychological (P)' (13 occurrences). The detailed results to our primary objective are presented in table 2.

In post hoc analyses, we described reasons to visit according to age group and gender transition. Results are presented in figures 1 and 2. Numbers were too small to run comparative analyses between subgroups.

\section{Transgender people's expectations}

Most respondents (43\%) visited their GP as soon as they needed, $25 \%$ delayed their visit and $17 \%$ had already
Table 1 Demographic characteristics of the study population, $\mathrm{N}=320$

\begin{tabular}{|c|c|}
\hline \multicolumn{2}{|l|}{ Age (n, \%) } \\
\hline $18-25$ & $107(33)$ \\
\hline $26-40$ & $101(32)$ \\
\hline $41-60$ & 77 (24) \\
\hline$>60$ & $32(10)$ \\
\hline NA & $3(1)$ \\
\hline \multicolumn{2}{|l|}{ Gender (n, \%) } \\
\hline Transfeminine ${ }^{*}$ & $181(57)$ \\
\hline Transmasculine† & $126(39)$ \\
\hline Other & $10(3)$ \\
\hline NA & $3(1)$ \\
\hline \multicolumn{2}{|l|}{ Employment status (n, \%) } \\
\hline In employment & $85(27)$ \\
\hline Student & $83(26)$ \\
\hline Unemployment & $57(18)$ \\
\hline Retirement & $26(8)$ \\
\hline In employment (short) & $17(5)$ \\
\hline Unemployment (invalid) & $17(5)$ \\
\hline Other & $32(10)$ \\
\hline NA & $3(1)$ \\
\hline \multicolumn{2}{|l|}{ Social security number (n, \%) } \\
\hline Non-gender compatible & $240(75)$ \\
\hline Gender compatible & $70(22)$ \\
\hline NA & $10(3)$ \\
\hline
\end{tabular}

*Binary or non-binary, for example, a trans woman/MtF/MtX/Mt*. †Binary or non-binary, for example, a trans man/FtM/FtX/Ft*. $\mathrm{NA}$, no answer.

given up on a consultation. The main reason for postponing or waiving a consultation was apprehension of the physician's remarks ( 47 occurrences among 151 entries). The second reason was financial issues (46 occurrences).

Regarding satisfaction, $53 \%$ of the respondents responded they were absolutely satisfied with the consultation, $31 \%$ that they were rather satisfied and $10 \%$ that they were rather unsatisfied. Among the respondents, $66 \%$ were addressed to using the right gender, and $27 \%$ were misgendered, although most respondents thought the misgendering was not malevolent.

Of the 320 respondents, 229 answered the open-ended question about problems they encountered during consultations at the GP's office. The most recurring problem was misgendering, with 87 occurrences, either during the visit (54) or when making the appointment (33). Seventy-four entries were people specifying they did not meet any problem with their GP. All problems encountered are listed in table 3.

Of the 320 respondents, 248 answered the open-ended question about their views of a satisfactory consultation (table 4). Lack of judgement/benevolence was the most 
Table 2 Transgender people's reasons to visit their general practitioner on their last visit, outside of transition-related reasons, classified by their International Classification of Primary Care, second version (ICPC-2) code

\begin{tabular}{lll}
\hline $\begin{array}{l}\text { ICPC-2 } \\
\text { code }\end{array}$ & Section & Occurrences (n) \\
\hline- & Process codes & 52 \\
A & General and unspecified & 23 \\
L & Musculoskeletal & 18 \\
\hline R & Respiratory & 15 \\
\hline P & Psychological & 13 \\
\hline D & Digestive & 8 \\
\hline X & Female genital & 6 \\
\hline K & Cardiovascular & 5 \\
\hline S & Skin & 4 \\
N & Neurological & 3 \\
\hline$Z$ & Social problems & 3 \\
\hline U & Urological & 2 \\
\hline B & Blood, blood-forming organs & 1 \\
& and immune mechanism & 1 \\
\hline F & Eye & 1 \\
\hline & Endocrine/metabolic and & \\
\hline
\end{tabular}

frequent answer (95 occurrences), before respect of their gender identity (75) and patient listening (70).

\section{DISCUSSION \\ Main findings}

We conducted a cross-sectional survey among transgender people in France to study their reasons for visiting their GP. Among the 320 respondents, $52 \%$ had last consulted their GP for a reason unrelated to gender transitioning. Among the cited reasons, the most frequent ICPC-2 codes were administrative and follow-up process and general and unspecified symptoms.

The most frequent problems encountered by respondents in primary care were misgendering and a lack of knowledge regarding transidentity from their primary care physician. But we also noted 25 occurrences of reported judgmental attitudes or inquisitiveness, and 20 occurrences when respondents were denied care or prescription because of their transidentity. In the 2011 study by Chrysalide, ${ }^{5} 16 \%$ of the 187 respondents had been denied care because of their transidentity, and $35 \%$ had given up on some healthcare needs because of their experience of healthcare providers' attitudes regarding transidentity. The discrimination faced by transgender people in healthcare settings can be explained in part by a lack of training of healthcare providers in genderaffirming healthcare; such a training should be included

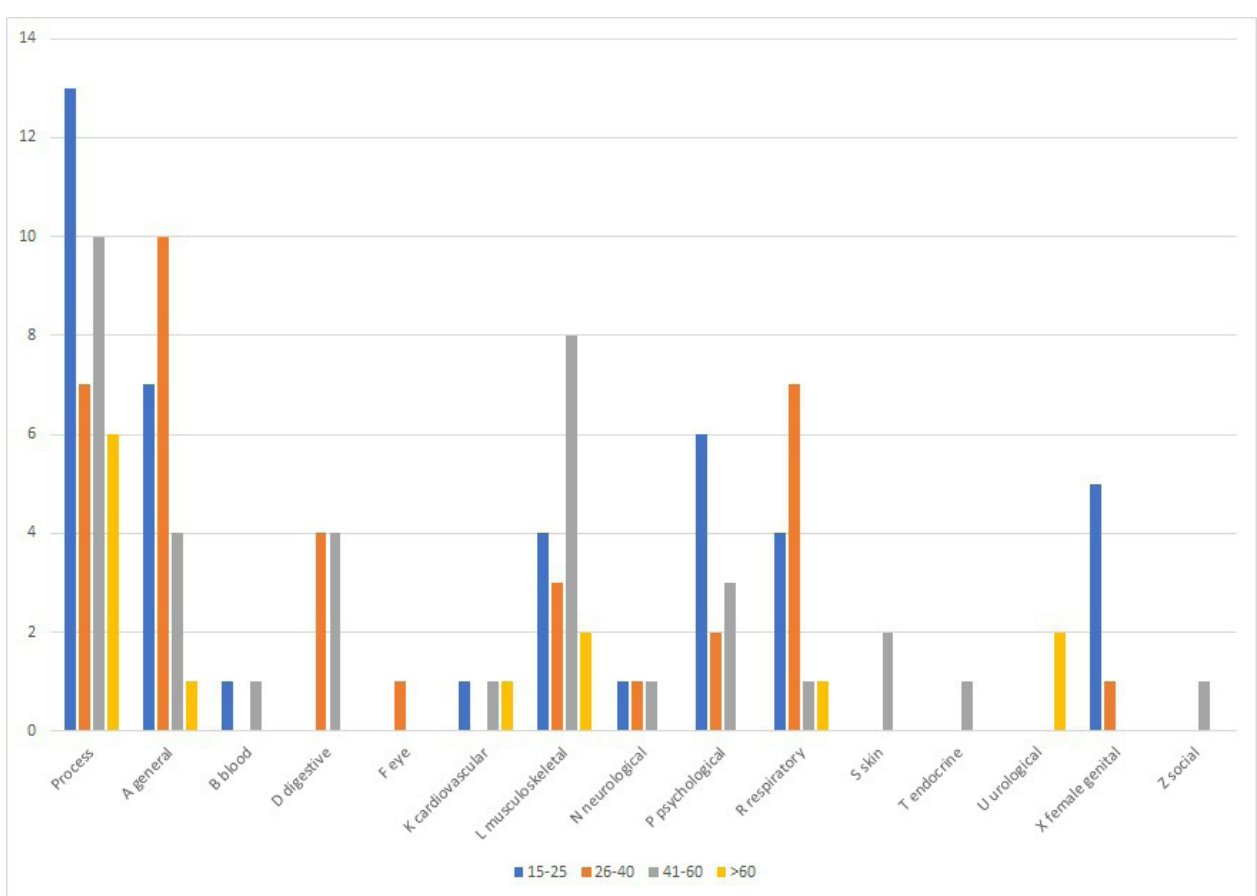

Figure 1 Reasons to visit by ICPC-2 code (International Classification of Primary Care) and by age group. 


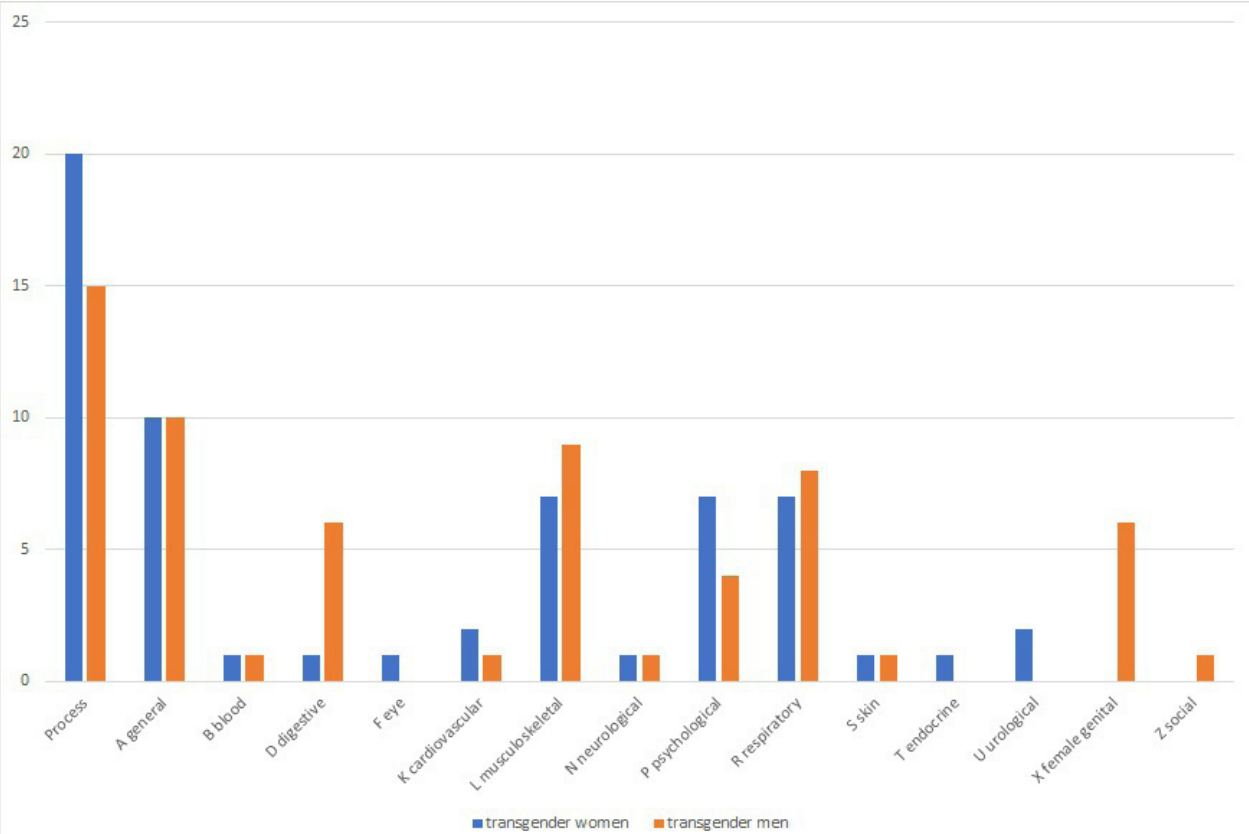

Figure 2 Reasons to visit by ICPC-2 code (International Classification of Primary Care) and by gender.

in healthcare students' curriculum. ${ }^{18}$ However, a recent study suggests that transphobia rather than lack of training predicts providers knowledge of transgender healthcare. ${ }^{19}$ Transphobia must be addressed in society and in medical education to improve access to care for transgender people.

The inadequation of the social security number with the gender identity can be a hindrance for transgender patients, in their relationship with their GP and in the process of civil registration. In our study, $75 \%$ of

Table 3 Problems encountered by transgender people when consulting in primary care

\section{Problems}

Occurrences

\begin{tabular}{ll}
\hline None & 74 \\
\hline Misgendering & 87 \\
\hline \multicolumn{1}{|c}{ During the visit } & 54 \\
\hline When making the appointment & 33 \\
\hline Lack of knowledge about transidentity & 65 \\
\hline \multicolumn{1}{|c|}{ Social aspects of transidentity } & 18 \\
\hline Medical aspects of transidentity & 15 \\
\hline \multicolumn{1}{|c|}{ No further detail } & 34 \\
\hline Judgmental attitude & 25 \\
\hline Inquisitiveness & 25 \\
\hline Care or prescription refusal & 20 \\
\hline Attitudes of other patients in the waiting & 9 \\
room & \\
\hline Attribution of any symptom to the transition & 5 \\
process & \\
\hline Other (unspecified) & 41 \\
\hline
\end{tabular}

respondents stated their social security number was not in accordance with their gender identity.

\section{Strengths and limitations}

To the best of our knowledge, this study is the first to explore transgender people's reasons for consulting a GP, especially outside of transition-related problems.

Since trans civil rights organisations were our most frequent relays, we must consider a selection bias. The snowball sampling probably did not reach the people who were most isolated and precarious. However, the snowball method was the only one allowing us to reach so many

Table 4 Characteristics of a satisfactory consultation for transgender people in primary care

\section{Characteristics}

Occurrences

$\begin{array}{lr}\text { Lack of judgement/benevolence } & 95 \\ \text { Respect of gender identity } & 75 \\ \text { Patient listening } & 70 \\ \text { No inquisitive question } & 39 \\ \text { Able to provide information on transition } & 34 \\ \text { Competence } & 30 \\ \text { Relationship with specialists } & 15 \\ \text { Ability to acknowledge patient's } & 15 \\ \text { information/knowledge } & 15 \\ \text { Same behaviour with trans or cis patients } & 13 \\ \text { Respect of body limits and consent } & 11 \\ \text { Research of aetiologies other than transition } & 11 \\ \text { Confidentiality } & 31 \\ \text { Other } & \end{array}$


people from a hidden population during a short time period. In comparison, organisation Chrysalide's survey ${ }^{5}$ in 2011 got 187 responses, and the INSERM study in 2011 got 381 responses. ${ }^{10}$ We tried to lower the selection bias by involving sexual and university health centres but got very few responses.

Memory bias is also present due to the retrospective aspect of our study but could be limited by the fact that $80 \%$ of the respondents' last consultation happened in the last 6 months. Desirability bias was lowered by the fact that the questionnaire was anonymous and that respondents were free not to answer any question that made them uncomfortable.

\section{Comparison to other studies}

The French Éléments de la Consultation en médecine générale (ECOGEN) study ${ }^{20}$ published in 2014 used the ICPC-2 to classify the reasons for 20613 consultations in primary care. In ECOGEN, the most frequent code was 'Process': treatment renewal. Then came 'General and unspecified', 'Cardiovascular', 'Respiratory' and 'Musculoskeletal' symptoms. A statistical comparison between our results and ECOGEN's would be difficult because of sample size difference. Moreover, the description in ECOGEN was prospective and systematic when our data collection was retrospective. The main differences in our results compared with ECOGEN's is a lower number of Cardiovascular codes and higher number of Psychological codes. This difference could be explained in part by a difference in the age of participants: almost $20 \%$ of ECOGEN participants were over 60 years old versus $10 \%$ in our study.

In the 2007 survey $^{9}$ conducted by trans organisations and HIV prevention centres, $86 \%$ of the respondents had a declared GP. They were $93 \%$ in our study. In Chrysalide's survey, ${ }^{5} 35 \%$ of the respondents recognised having given up on primary care because of their apprehension of the medical staff's judgement. They were $17 \%$ in our study. These results may reflect a better social acceptance of transgender people and awareness about transgender issues, leading to a better inclusion in the healthcare system.

In our study, $53 \%$ of the respondents declared being very satisfied by the last consultation with their GP, and $31 \%$ were rather satisfied. French's Research, Study, Evaluation and Statistics Direction (Direction de la recherche, des études, de l'évaluation et des statistiques, DRESS) published a report ${ }^{21}$ in 2017 on the general population's opinion about their GP. Of the 3023 respondents, $34 \%$ were very satisfied and 54\% rather satisfied with their GP. In both this study and ours, the satisfaction rate is close to $80 \%$.

Our findings were consistent with a recent qualitative study focusing on transgender persons' experiences in a family medicine clinic ${ }^{22}$ where results showed that a positive experience included 'respecting the gender identities of every patient and focusing on the whole person-not the transgender status of the patient', in other words, providing patient-centred care. In other recent studies exploring transgender patients' expectations regarding their primary care/family physician, patients expect their family physician to be able to provide comprehensive care, including routine primary care and transgenderspecific healthcare ${ }^{23}$ (eg, hormone therapy). This could help not delaying care due to fear of discrimination in the healthcare setting. ${ }^{24} \mathrm{~A}$ greater perceived knowledge of transgender health issues by their family physician alleviates the discomfort reported by transgender patients when discussing such issues, ${ }^{25}$ adding to the case of specific training in transgender issues needed to family physicians in training.

\section{Implications of the study}

Our study found that when their medical needs are not related to gender transition, transgender people go to their GP for reasons which seem similar to those of the general population. However, half of the reasons to visit their GP were related to transition. The definition of 'related' or 'unrelated' to transition was given by the respondents themselves when they answered the survey. No interpretation was made by the investigators when analysing the data. Respondents expected their transidentity not to be the sole concern of their GP, with a respect for their intimacy when the reason for visit is unrelated to gender-affirming healthcare. However, they expected their GP to be aware of the specificities of transgender healthcare to avoid discrimination and negative attitudes. Lack of specific knowledge in primary care providers about transgender healthcare (and the subsequent need for transgender patients to educate their physician) is associated with a more frequent postponing or not seeking of medical care. ${ }^{26}$

Our findings add to the body of literature on patientcentred primary care for transgender patients. Primary care providers, including GPs, must be able to provide routine primary care for transgender patients, for either transition related or unrelated healthcare. Such healthcare requires specific knowledge, and patient-centred care is particularly appropriate in general practice. Family medicine trainees should benefit from medical education focusing on transgender-specific healthcare and issues.

\section{Twitter Christine Maynié-François @GeluleMD}

Acknowledgements The authors would like to acknowledge and thank the members of the association Chrysalide who discussed and worked on the study protocol and questionnaire. The authors thank the local College of teaching general practitioners (Collège lyonnais des généralistes enseignants, CLGE) who covered publication fees.

Contributors All authors (MG, SO, MF, CM-F) equally participated in the protocol design. MG and SO conducted the study. All authors (MG, SO, MF, CM-F) analysed the results. MG, S0 and CM-F wrote the first draft of the paper. All authors (MG, SO, MF, CM-F) reviewed the different versions of the paper, and approved the final version of the paper.

Funding The authors have not declared a specific grant for this research from any funding agency in the public, commercial or not-for-profit sectors. Funding was provided by the local College of teaching general practitioners (Collège lyonnais des généralistes enseignants, CLGE) to cover publication fees.

Competing interests None declared.

Patient consent for publication Not required. 
Ethics approval The study protocol was approved by the Ethics Committee of Lyon University College of General Practice (IRB: 2017-09-05-07) and by the CNIL (National Commission for Data and Liberties Protection).

Provenance and peer review Not commissioned; externally peer reviewed.

Data availability statement Data may be obtained from a third party and are not publicly available. Following the requirements of the french CNIL, data are not publicly available.

Supplemental material This content has been supplied by the author(s). It has not been vetted by BMJ Publishing Group Limited (BMJ) and may not have been peer-reviewed. Any opinions or recommendations discussed are solely those of the author(s) and are not endorsed by BMJ. BMJ disclaims all liability and responsibility arising from any reliance placed on the content. Where the content includes any translated material, BMJ does not warrant the accuracy and reliability of the translations (including but not limited to local regulations, clinical guidelines, terminology, drug names and drug dosages), and is not responsible for any error and/or omissions arising from translation and adaptation or otherwise.

Open access This is an open access article distributed in accordance with the Creative Commons Attribution Non Commercial (CC BY-NC 4.0) license, which permits others to distribute, remix, adapt, build upon this work non-commercially, and license their derivative works on different terms, provided the original work is properly cited, appropriate credit is given, any changes made indicated, and the use is non-commercial. See: http://creativecommons.org/licenses/by-nc/4.0/.

ORCID iD

Christine Maynié-François http://orcid.org/0000-0003-2346-6199

\section{REFERENCES}

1 Santé HAde. Situation actuelle et perspectives d'évolution de la prise en charge médicale du transsexualisme en France. Service évaluation des actes professionnels (French) 2009.

2 World professional association for transgender health. Standard of care for the health of transsexual, transgender, and gender nonconforming people, 7th version 2012.

3 Bockting WO, Miner MH, Swinburne Romine RE, et al. Stigma, mental health, and resilience in an online sample of the US transgender population. Am J Public Health 2013;103:943-51.

4 Meyer IH. Prejudice, social stress, and mental health in lesbian, gay, and bisexual populations: conceptual issues and research evidence. Psychol Bull 2003;129:674-97.

5 Association Chrysalide. Enquête Santé trans (French), 2011. Available: http://chrysalidelyon.free.fr/fichiers/doc/santetrans2011. pdf

6 McNeil J, Bailey L, Ellis S, et al. Transgender equality network Ireland. Speaking from the margins : trans mental health and wellbeing in Ireland, 2013. Available: http://www.teni.ie/attachments/ 5bdd0cd5-16b6-4ab6-9ee6-a693b37fdbcf.PDF

7 Gonzales G, Henning-Smith C. Barriers to care among transgender and gender Nonconforming adults. Milbank Q 2017;95:726-48.

8 Nakad L. Quels sont les motifs de consultation des personnes transgenres : revue systématique de la littérature [dissertation].
Paris: Université Paris Diderot, 2015. http://www.bichat-larib.com/ publications.documents/4950_NAKAD_these.pdf

9 d'Almeida Wilson K, Lert F, Berdougo F. Transsexuel(le)s : conditions et style de vie, santé perçue et comportements sexuels. Résultats d'une enquête exploratoire par Internet, 2007 (French). BEH 2008;27.

10 Giami A, Beaubatie E, Le Bail J. Caractéristiques sociodémographiques, identifications de genre, parcours de transition médicopsychologiques et $\mathrm{VIH} /$ sida dans la population trans. Premiers résultats d'une enquête menée en France en 2010 (French). BEH 2011;42.

11 Wylie K, Knudson G, Khan SI, et al. Serving transgender people: clinical care considerations and service delivery models in transgender health. Lancet 2016;388:401-11.

12 Whitehead J, Shaver J, Stephenson R. Outness, stigma, and primary health care utilization among rural LGBT populations. PLoS One 2016;11:e0146139.

13 Shires DA, Stroumsa D, Jaffee KD, et al. Primary care clinicians' willingness to care for transgender patients. Ann Fam Med 2018;16:555-8.

14 Shires DA, Stroumsa D, Jaffee KD, et al. Primary care providers' willingness to continue gender-affirming hormone therapy for transgender patients. Fam Pract 2018;35:576-81.

15 Gahagan J, Subirana-Malaret M. Improving pathways to primary health care among LGBTQ populations and health care providers: key findings from nova Scotia, Canada. Int $J$ Equity Health 2018;17:76.

16 Hughes JP, Emel L, Hanscom B, et al. Design issues in transgender studies. J Acquir Immune Defic Syndr 2016;72 Suppl 3:S248-51.

17 Classification Committee of the World Organization of Family Doctors (WICC). ICPC-2: International classification of primary care. Oxford: Oxford University Press, 1997.

18 de Vries E, Kathard H, Müller A. Debate: why should gender-affirming health care be included in health science curricula? BMC Med Educ 2020;20:51.

19 Stroumsa D, Shires DA, Richardson CR, et al. Transphobia rather than education predicts provider knowledge of transgender health care. Med Educ 2019;53:398-407.

20 Letrilliart L, Supper I, Schuers M. ECOGEN : Etude des éléments de la consultation en médecine générale (French). Exercer 2014:148-57.

21 Castell L, Dennevault C. Direction de la recherche des études de l'évaluation et des statistiques. Qualité et accès aux soins : que pensent les Français de leurs médecins? Etudes et Résultats; 1035 (French), 2017. Available: http://drees.solidarites-sante.gouv.fr/IMG/ pdf/er_1035.pdf

22 Hinrichs A, Link C, Seaquist L, et al. Transgender and gender Nonconforming patient experiences at a family medicine clinic. Acad Med 2018;93:76-81.

23 Bell J, Purkey E. Trans individuals' experiences in primary care. Can Fam Physician 2019;65:e147-54.

24 Kattari SK, Atteberry-Ash B, Kinney MK, et al. One size does not fit all: differential transgender health experiences. Soc Work Health Care 2019;58:899-917.

25 Bauer GR, Zong X, Scheim Al, et al. Factors impacting transgender patients' discomfort with their family physicians: a RespondentDriven sampling survey. PLoS One 2015;10:e0145046.

26 Jaffee KD, Shires DA, Stroumsa D. Discrimination and delayed health care among transgender women and men: implications for improving medical education and health care delivery. Med Care 2016;54:1010-6. 